\title{
Introduction to the Guest Editors
}

\section{Renata S. Maricevich, MD, and Tuan A. Truong, MD}

\author{
Larry H. Hollier, Jr., MD, FACS ${ }^{1}$ \\ ${ }^{1}$ Division of Plastic Surgery, Baylor College of Medicine, Houston, \\ Texas \\ Semin Plast Surg 2017;31:65-66.
}

I want to thank Drs. Renata Maricevich and Tuan Truong for serving as guest editors for this issue of Seminars in Plastic Surgery and the outstanding group of authors they have invited to contribute to this issue on facial trauma.

Dr. Maricevich is currently an Assistant Professor of Surgery in the Division of Plastic Surgery of the Michael E. DeBakey Department of Surgery at Baylor College of Medicine and Texas Children's Hospital.

She was born and raised in Recife, Brazil, where she also received her medical degree from the Universidade Federal de Pernambuco. She moved to the United States to pursue her training and completed General Surgery and Plastic Surgery residencies at the Mayo Clinic in Rochester, Minnesota, followed by a Pediatric Craniofacial Fellowship at the University of Pittsburgh Medical Center. Her clinical interests are in craniofacial and cleft surgery, as well as pediatric surgery and vascular anomalies.
Dr. Truong is a native Texan who earned his medical degree from the University of Texas Southwestern Medical School in Dallas. He completed his General Surgery residency at the University of Florida in Jacksonville and his Plastic Surgery residency at the Mayo Clinic Arizona in Phoenix. He then completed his fellowship in Craniofacial and Pediatric Plastic Surgery at Dell Children's Medical Center in Austin, Texas, where he received comprehensive training in the treatment of a wide variety of pediatric and craniofacial anomalies.

As a Rice alumni, he is fortunate to return to Houston and Texas Children's Hospital, where he is part of a diverse and multifaceted team of specialists dedicated to improving the care of children in the greater Houston area. Dr. Truong is an Assistant Professor of Surgery in the Division of Plastic Surgery at Baylor College of Medicine. His special interests are cranial vault remodeling, facial fractures, midfacial and mandibular distraction, orthognathic surgery, and virtual surgical planning. Larry H. Hollier, Jr., MD, FACS, Division of Plastic Surgery, Baylor Maricevich, MD, and Tuan A. College of Medicine, TCH Clinical Truong, MD Care Center, 6701 Fannin Street, Suite 610, Houston, TX 77030 (e-mail: larryh@bcm.tmc.edu). 